\title{
Búsqueda, regreso y agencia para una escritura quichua santiagueña: Mario Tebes (1927-2009)
}

\section{Héctor Andreani}

Universidad Nacional de Santiago del Estero (UNSE)

Correo electrónico: sachahector@gmail.com
Recibido:

22 de noviembre de 2017 Aceptado:

8 de noviembre de 2018

\section{Resumen}

Mario Tebes (1927-2009) fue un escritor bilingüe quichua-castellano nacido en el extremo norte del departamento de Figueroa, Santiago del Estero, Argentina. Al final de su vida, publicó su memorial Castañumanta Yuyayniy (Mi recuerdo del Castaño, 2009), la primera obra en prosa "de autor" en lengua quichua. En la mesopotamia santiagueña y en el conurbano bonaerense hay sectores poblacionales que siguen siendo bilingües, con un complejo proceso sociohistórico de asimetrías en el orden de los usos y sentidos respecto del quichua y el castellano. Nuestra hipótesis es que Castañumanta no trata de un rescate folklórico del quichua, sino que esas experiencias son la reconstrucción de evidencias de una trama social que sostiene a dicha lengua. Las estrategias discursivas de Tebes y su trayecto singular implican un deber ser (cómo escribir en) quichua, con posicionamientos implícitos sobre otros escritores bilingües. Este análisis permite ver evidencias de una intensa postura identitaria.

\section{Search, return and agency for a writing in Quichua Santia- gueño language: Mario Tebes (1927-2009)}

\begin{abstract}
Mario Tebes (1927-2009) is a bilingual Quichua-Spanish writer born in the northern extreme of Figueroa department, Santiago del Estero (Argentina). Towards the end of his life, he published his memoir Castañumanta Yuyayniy (My memory of El Castaño, 2009), the first prose "author" work in Quichua language. In Santiago del Estero's Mesopotamia and in Buenos Aires conurbation there are portions of population that remain bilingual, with a complex socio-historical process of asymmetries within the order of uses and meanings concerning Quichua and Spanish. Our hypothesis is that Castañumanta does not deal with a folklore-related rescue of the Quichua, but with the fact that those experiences are the reconstruction of evidences of a social framework that
\end{abstract}

\section{Palabras clave}

Escritura quichua; Trama sociolingüística; Trayectoria vital; Discurso identitario; Reglas de escritura

\section{Key words}

Quichua script; Sociolinguistic framework; Life trajectory; Identity discourse; Writing Rules 
Palavras-chave

Escrita quichua; Trama sociolingüística. Caminho de vida; Discurso de identidade; Reglas de escritura supports that language. Tebes's discursive strategies and his singular trajectory imply an ought-to-be (how to write in) Quichua, with implicit assumptions on other bilingual (other "quichuistas") writers. This analysis enables the realization about evidence of an intense identity position.

\section{Pesquisa, retorno e agência para escrever em quichua santia- gueña: Mario Tebes (1927-2009)}

\section{Resumo}

Mario Tebes (1927-2009) é um escritor quichua-espanhol bilingue nascido no extremo norte do departamento de Figueroa, Santiago del Estero (Argentina). No final de sua vida, ele publicou seus memórias Castañumanta Yuyayniy (Minha memória de El Castaño, 2009), o primeiro trabalho de "autoria" em língua quichua. Na Mesopotâmia de Santiago del Estero e na conurbação de Buenos Aires há porções de população que permanecem bilíngües, com um processo sócio-histórico complexo de assimetrias dentro da ordem de usos e significados relativos Quichua e Espanhol. Nossa hipótese é que Castañumanta não lida com um resgate do Quichua relacionado ao folklore, mas com o fato de que essas experiências são a reconstrução de evidências de uma trama social que suporte essa linguagem. As estratégias discursivas de Tebes e a sua trajetória singular implicam um dever-ser (como escrever) quichua, com pressupostos implícitos em outros escritores bilíngües (outros "quichuistas"). Esta análise permite ver evidências de uma posição de identidade intensa.

\section{Introducción}

\begin{abstract}
"Manami atun ruwakunaaspachu nini creesqayta aykappas kachun pillatapas siruipunanta imallapaspa ká cuentasusqaykichisqa. Munayman ká cuentasqayqa qaachikunanta imaynachus kawsaq karanku y kichwataqa rimaq karanku unay shalakus Figueroamanta y munaymanpasmi yanapa kapukunanta yachanaaqkunapaq imachus y mayqamachus kunan kichwa rimakoqqa astaanmanta wakchayas kichkasqanta/Modestamente supongo que alguna vez este libro a alguien le puede servir para algo. Me gustaría que lo que cuento aquí muestre cómo vivían y cómo hablaban la quichua los viejos shalacos de Figueroa y también me gustaría que sirviera de ayuda a los que quieran saber por qué y hasta qué punto el idioma que se habla se está empobreciendo cada vez más”.
\end{abstract}

(Tebes, 2009, p. 29)

1. Pozo del Castaño es una zona del departamento Figueroa, a 150 $\mathrm{km}$ al norte de Santiago Capital. Sus pobladores, al ubicarse a los márgenes del extenso río Salado, reciben una marcación desde hace medio siglo al ser considerados shalacos (hipocorístico de "salado"), que fue peyorativo durante mucho tiempo pero ahora funciona como diacrítico identitario en espacios extraprovinciales (por ejemplo,

los migrantes shalacos residentes en Buenos Aires). Tebes mismo expone en su introducción que esta es una obra de un shalaco.
En 2009 conocí un libro muy singular, Castañumanta Yuyayniy (en castellano, Mi recuerdo del Castaño), ${ }^{1}$ escrito íntegramente en quichua, del hablante bilingüe Mario Tebes. El libro puede ser ubicado dentro de género testimonial: una heterogeneidad de situaciones y anécdotas en un memorial quichua del autor. Cuando vino a Santiago en 2009, logré entrevistarlo en un ambiente muy ameno, días antes de presentar su libro en la Universidad Nacional de Santiago del Estero (UNSE). Tebes falleció meses después, a los 82 años, en Buenos Aires. 


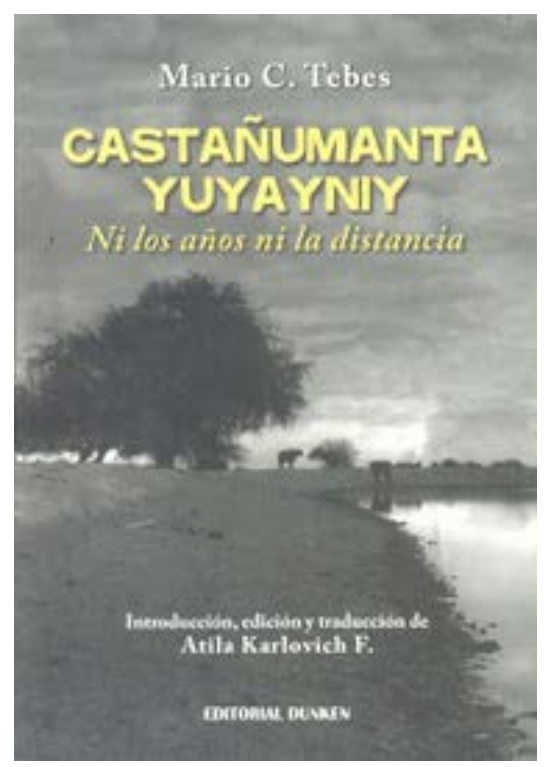

Figura 1. Tapa de libro

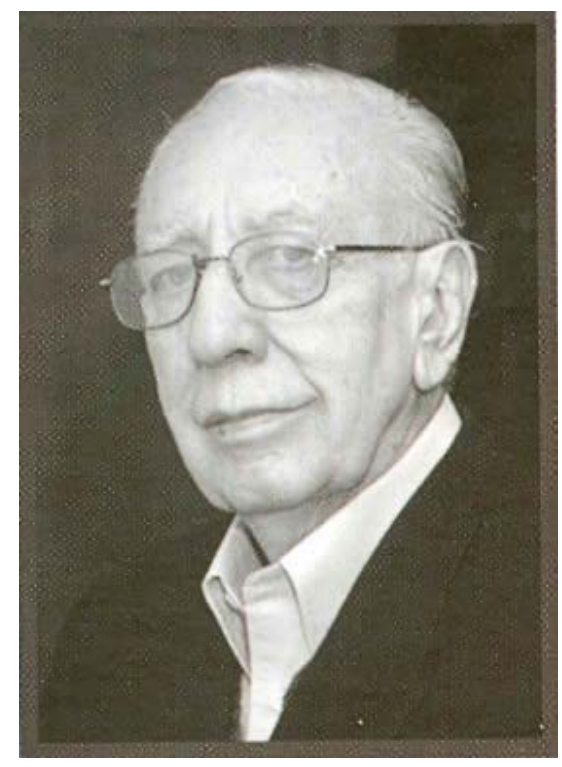

Figura 2. Foto del autor.

Había "algo" más allá de la sencillez aparente de sus relatos. Durante mucho tiempo no lograba "ingresar" al sentido profundo de estos relatos quichuas, dada una aplicación inadecuada de la crítica literaria. Así, modifiqué el planteo y traté de establecer un cruce entre tres "ejes" posibles: la configuración sociohistórica de este bilingüismo, los escritos quichuas del siglo XX y la trayectoria del autor.

Aquí comienza la formulación de nuestro problema de investigación. Como sucede en muchas lenguas nativas $-y$ también con muchos estudios sociolingüísticos que las abordan-, suele argumentarse que la escritura sería un indicador de revitalización lingüística. Esa creencia también es intensa en los intelectuales nativos o, en nuestro caso, pobladores criollos que hablan una lengua nativa, como lo son Tebes y los demás escritores quichuistas del siglo XX. Sin embargo, se sabe que ninguna escritura asegura de por sí la revitalización lingüística (Hornberger, 1995; Vigil, 2004).

Nuestra hipótesis es que las escrituras literarias en lenguas periféricas (mejor dicho, la creencia nativa en esas escrituras) están atravesadas por la asimetría sociohistórica en la que se encuentran relegadas: esa configuración sociolingüística impacta notoriamente en el tipo de uso de la lengua, y por ello deviene discurso identitario. Es el conflicto lingüistico (Aracil, 1976) y no las reglas del campo literario, lo que constituye a estas escrituras. Como describiremos, bajo Castañumanta no hay un rescate folklórico del quichua, sino que esas experiencias son la reconstrucción de evidencias -por parte de la memoria del autor- de una trama social que sostiene a dicha lengua. No se trata de una mirada provinciana, de identidades políticas hegemónicas o de imaginarios culturales cristalizados a nivel local. El análisis muestra que, bajo la sencillez aparente de un manojo de relatos orales, surge una intensa postura identitaria de otra índole.

Surgen algunos desafíos: 1) cómo acceder a una escritura y una lengua que son periféricas al extremo, porque este tipo de escrituras es invisible en el plano social pero, paradójicamente, la lengua quichua (sobre todo cuando es lengua escrita) porta un valor muy significativo para el imaginario cultural del NOA;2) cómo analizar las acciones de hablantes de esta lengua que "necesitan" participar en 
un espacio de escritura; 3) cómo definir un contexto: el proceso sociolingüístico de larga duración que configura la lengua desde los dispositivos estatales.

Siguiendo ese imaginario compartido por los hablantes escolarizados de muchas lenguas minorizadas en el mundo, esa reconstrucción propuesta por Tebes para su Castañumanta permite observar una ética de escritura, es decir, un camino que trata de discernir por dónde debería ir la lengua mediante la escritura. Tebes intenta una resolución simbólica - por la vía de la escritura quichua - ante ese conflicto lingüistico de larga data. Esto permite entender cómo y por qué Tebes construye su escritura, pero también cuál podría ser la motivación profunda de quienes se constituyen como agentes de una escritura nativa.

\section{Proceso social y escrituras previas}

Según estimaciones, el quichua santiagueño (QS) sería hablado en Santiago del Estero (SdE) por más de 150.000 personas (de las cuales casi la totalidad es bilingüe) (Albarracín, 2009). El proceso histórico de "blanqueamiento" de la formación nacional que borró todo trazo étnico (Chamosa, 2008) tuvo otros matices en SdE: la identidad santiagueña constituyó una problematización para la identidad homogénea nacional, y el quichua se comportó hasta hoy como un elemento significativo en esa formación discursiva (Grosso, 2008). Esta lengua tiene una paradoja histórica, que bien vale describir a los fines de esta investigación: se la considera una "isla" lingüística que logró mantenerse cuando otras lenguas indígenas del NOA habían desaparecido, dado que el quichua habría sufrido un proceso de desmarcación indígena durante el siglo XIX (cf. Stark, 1985). Según la interpretación de Karlovich (2006) sobre un trabajo de Landsman (2000), esto ocurrió por una alianza implícita entre clero, caudillos y campesinos contra el avance modernizador porteño de la Generación del 80. Así, se habría mantenido el quichua en SdE, pero como lengua "criolla" y no indígena o, en todo caso, una lengua indígena hablada por criollos.

Como variedad dialectal se manifiesta en usos efectivos desde tiempos prehispánicos hasta los tiempos actuales, pero tuvo flujos de hablas históricamente discontinuos y dinámicos (Grosso, 2008). Algunos bilingües ejercieron el poder político desde el siglo XIX (gobernadores, jefes territoriales, posteriormente intendentes, rectores universitarios), y miles de ellos fueron agentes educativos. Sectores dominantes la marcaron durante el siglo $\mathrm{XX}$ como lengua cristalizada en el campo folklórico asociada a la producción de coplas, pero principalmente se la vinculó con un bilingüismo iniciático desde la llegada de los españoles, que sería el supuesto origen de la argentinidad (Kuz, 2001), y posee referencias muy significativas en varios textos literarios y ensayísticos en todo el siglo XX. En la actualidad, la lengua es utilizada como un recurso souvenir de ámbitos culturales (secretarías estatales, boletines, revistas culturales, entre otros), pero frecuentemente surgen interpelaciones desde las capas precarizadas de docentes bilingües hacia los estamentos ministeriales. No obstante, "la quichua" jamás fue un elemento distintivo de ascensos y roles sociales, y la gran mayoría de quienes siguen siendo bilingües quedaron relegados en capas proletarizadas muy empobrecidas de toda la mesopotamia santiagueña.

2. Tomamos el concepto de bilingüismo situado de Unamuno (2012), quien lo piensa desde la sociolingüística interaccional, pero lo resignificamos como un aspecto más de un proceso territorial.
El tipo de conflicto lingüístico descripto sobre el quichua ${ }^{2}$ no puede ser desligado de condiciones materiales concretas. SdE es una provincia económicamente periférica de Argentina, marcada por un modelo agroforestal proveniente de capitales extranjeros desde fines del siglo XIX (Dargoltz, 2003), sin desarrollo 
industrial sostenible y con un capitalismo agrario local muy gradual (Tasso, 2007). Cuando cayó la producción forestal, la estructura socioeconómica se modificó hacia una intensa dependencia presupuestaria del Estado nacional, mediante un proceso discontinuo de modernización periférica desde la década del cuarenta hasta fines del siglo XX (Martínez, 2013a). El modelo agroforestal y la explotación hacia sus obreros fue denunciada como crisis socioecológica irreversible por muchos intelectuales locales (Di Lullo, 1937) y por la prensa porteña (Tasso, 2011). Aunque durante toda la primera mitad del siglo XX se mantuvo un monolingüismo social quichua en gran parte del territorio provincial, muy recurrente en las memorias de pobladores ancianos (Andreani, 2013), no aparecen referencias críticas sobre la situación de dicha lengua. Tenemos entonces esta configuración de conflicto lingüístico (Aracil, 1965), gradualmente constituido entre agentes estatales, inmigrantes y poblaciones rurales, que creció en intensidad desde la época de la modernización estatal de mediados del siglo XX. Ese proceso productivo rural pasó, en el amplio territorio del Chaco santiagueño y siguiendo el curso del río Salado, desde una producción basada en la recolección de miel y algarroba (Bilbao, 1974; Farberman, 2005); hasta la década del ochenta del siglo XIX, cuando se expandió la producción ganadera; y una tercera etapa caracterizada por la explotación forestal mencionada (ver el cuadro final de la figura 4). En el caso del extremo noroeste provincial (hoy departamentos de Figueroa, Alberdi, Jiménez y Moreno), esta última etapa se intensificó entre fines de los años veinte y durante toda la década del treinta.

Tebes provenía de una trama directamente emparentada con los hermanos Manuel y Antonino Taboada, político y hacendado respectivamente (también bilingües), cuyo ciclo político se cerró abruptamente en 1875. Fue nieto de Miguel Tévez, pero criado por su socio en comercio rural, Macario González. Se trataba de una trama social de pospatronazgo (descripta detalladamente en Castañumanta) extendida en numerosas familias emparentadas entre patrones de estancia, capataces, lenguaraces (traductores-mediadores), peones, obreros forestales, conchabados y nuevos agentes de la pequeña burguesía ascendente del comercio rural, extranjeros europeos y árabes (devenidos neoquichuahablantes) y, sobre todo, las instalaciones obrajeras de las décadas del veinte y del treinta: todo esto compone el escenario social de un monolingüismo social quichua y un bilingüismo Q-C que fue territorializando mientras el Estado desarrollaba sus dispositivos laborales y escolares (Andreani, 2013). Así Tebes vivió su infancia y juventud, y toda esta configuración sociopoblacional es el "referente empírico" del memorial.

Entre las décadas del sesenta y del setenta "la quichua" se visibilizó mucho más, pero no operó como escritura sino como otros géneros: música folklórica, poesía gauchesca y emisiones radiales locales. Es decir, "la quichua" se consolidaba como elemento identitario dentro del campo folklórico y del mercado discográfico que dio sostén al boom del folklore desde la década del sesenta. En ese contexto, se destaca ese colectivo radial que se llamó Audición Radial Alero Quichua, creado a fines de los sesenta y conformado por varios agentes culturales; todos bilingües rurales residentes en la ciudad, asalariados urbanos con movilidad social (empleados de comercio, empleados estatales, docentes) quienes sostienen una actividad que ya lleva cuatro décadas. Ese fue el núcleo de gestiones culturales de bilingües, incluido el mismo Tebes, aunque en todo momento su posición fue muy periférica a ese sector porque (como veremos) nunca la capitalizó con los atributos propios del folklore. 
Es relevante aquí consignar las discontinuas obras quichuas a lo largo del siglo XX. La poesía de transmisión oral - en quichua, en castellano y bilingüe- que aparece en cancioneros y vocabularios - compuestos por autores anónimos, transmitidos de boca en boca y por cantores populares semiprofesionales - fue recopilada por notables folkloristas y maestros de escuela durante la primera mitad del XX (cf. Chein, 2005; Tebes y Karlovich, 2006; Chamosa, 2012). En las escrituras predominó una perspectiva desindianizada de la cultura folklórica (Canal Feijóo, 1937, 1951; Di Lullo, 1937; Abregú Virreyra, 1942; López, 1950 [1938]; Bravo, 1956; 1965) en el período de "emergencia" entre la década del treinta y la del cincuenta y en consonancia con la antropología del rescate, sobre todo en el registro de relatos orales (cf. Chein, 2005). En la literatura castellana aparece como figura principal Jorge W. Ábalos: en Shunko (1949) y Shalacos (1975), las vivencias de los docentes rurales con sus alumnos bilingües de mediados del siglo XX muestran actitudes sobre el quichua, pedagogías humanistas y algunos diálogos bilingües. El primer texto quichua publicado fue una leyenda (con algunos elementos de espanto) dentro de un libro de leyendas en castellano, El desierto Saladino, del maestro Ángel Luciano López, en 1938. Pero la primera obra - deliberada como tal - de un quichuahablante fue Pallaspa Chinkas Richkajjta (Juntando lo que se va perdiendo, 1953) del atamisqueño José Antonio Sosa. Se trata de un poema épico-narrativo en el cual un muchacho tiene un encuentro con el diablo en la Salamanca: ese texto evidenciaba por primera vez una objetivación de la conciencia del quichua como lengua de escritura. Los textos de Andrónico Gil Rojas $(1954,1962)$ se caracterizan por una oralidad saturada y florida en la que el quichua aparece inserto dentro de diálogos en castellano. Enrique Ruiz Gerez fue tal vez el primer quichuista - también figueroano- que escribió en clave folklórica muy explícita sus textos quichuas (1963). Pero otro figueroano, Vicente Salto, pariente de Tebes, escribió el pequeño poemario Para Yaku (Agua de lluvia, 1969), y es considerado el juglar de más vuelo poético dentro del universo discursivo quichua (cf. Karlovich 2006, p. 37). Dúo Sachero Sixto-Violín fue una compilación de canciones y coplas del músico Sixto Palavecino (1997), quien también publicó dos versiones quichuas del Martín Fierro (Hernández, 1991, 2007). Aldo Tévez, con su poemario Ckomer Pacha (Tiempo verde, 1996) transitó por diversos géneros, traduciendo a poetas extranjeros al quichua, con letras de tangos y otros poemas que adquieren un tinte épico hacia el espacio andino.

De esta breve cronología surgen datos significativos: la lengua quichua fue una marcación gradualmente visualizada desde fines del siglo XIX en adelante, y no sufrió los dispositivos estatales de exterminio como sucedió con otras lenguas indígenas de Argentina durante el siglo XX. Una tradición oral muy dinámica fue el germen de los primeros textos hasta mediados de esta centuria, pero también hubo un gradual pasaje de la oralidad en el texto a la conciencia escritural, porque desde los años treinta tuvo lugar una presión estatal negativa sobre esta lengua (cf. Karlovich 2006). En cada obra quichua publicada, hubo intentos de innovación estética o de recopilación consciente de la lengua, pero en todos ellos hay una conciencia de escritura que está atravesada por el problema del desplazamiento lingüístico. Por ejemplo, Sosa, ya en su pequeño prólogo fundacional, diagnosticaba que sin escritura y sin escolarización, la "expresión verbal (...) se iba perdiendo" (1953, p. 1). Ahora bien, si antes hubo intentos de innovación estilística en quichua (y ciertamente los hubo, y muy vanguardistas, como la poesía de Tévez), nos preguntamos por qué la sencillez formal de los relatos de Castañumanta se comporta como una innovación más eficaz que las anteriores. 


\section{Castañumanta yuyayniy}

El libro está organizado como un memorial de anécdotas y cuentos, elaborados como simples relatos, casi sin usar recursos propios del género literario. Toda la producción de Tebes está íntegramente escrita en quichua, y la traducción al castellano estuvo a cargo de quien fuera su colaborador e investigador colombiano Atila Karlovich. Tebes es bilingüe, como casi la totalidad de la población que habla quichua, sin embargo, su decisión fue escribir completamente $^{3}$ en quichua, incluyendo dedicatorias e introducción. El único antecedente de una escritura completamente monolingüe quichua es la del poemario narrativo de Sosa en 1953 (ya sabemos que Tebes conoce perfectamente esta obra). Una matriz oralizante recorre todo: el narrador está relatando en el rol de quien recuerda, y se dispone a contar la anécdota. La oralidad está directamente vinculada a la autenticidad. Pero no es oralidad recopilada, sino reconstruida.

Dice la traducción en su prólogo: "Modestamente supongo que alguna vez este libro a alguien le puede servir para algo". ${ }^{4}$ Esa modestia es un valor para el escritor quichuista. Algo también valorado en ese espacio: su carácter. "Mario [Tebes] era serio, humilde y bondadoso hasta los tuétanos", según Karlovich (comunicación personal). No es un aspecto banal, sino un atributo que tiene causas concretas que iremos desarrollando en este trabajo. Tebes pide a los lectores leer en clave de lengua aquello que parece referirse a otra situación. Hay muchas escenas en las que la lengua no es objeto central. Entre otros:

》 un avión que surcó el cielo de Figueroa por primera vez en los años treinta, y una señora creía que era el auto volador de un comerciante zonal;

" la biografía amorosa de una tía cercana;

" varias anécdotas humorísticas de velorios;

" una pelea de boxeo en un pueblo lejano entre un "negro" y su tío;

" un pariente que robaba trenes junto con el conocido bandolero Matecocido;

" la descripción pormenorizada de una reunión familiar con todos los recursos de abundancia del pospatronazgo, pero atravesados por la cultura shalaca;

" la vida del Tata Gaya, un anciano quichuista que convivió con indígenas en Chaco

" la vida de Clámades Quiña, un fanfarrón que decía ser "cazador de tigres";

" una extraña situación en la que un "indio Mataco" apareció tiritando de frío en el patio de su casa; a la mañana siguiente escapó "hacia el Chaco" (Tebes, 2009, p. 115). Este último texto evidencia notablemente la marca de desindianización propia de esta sociedad shalaca.

Sin embargo, cada texto en quichua debe ser leído en clave de texto narrado oralmente de acuerdo con el contexto figueroano de los años treinta y cuarenta. Dadas sus reflexiones enriquecidas con detalles, es posible denominarlas como memorial cuasietnográfico: trayectos de vida, conexiones entre vecinos, familiares y conocidos, y algunos escenarios porteños para justificar el trayecto del propio Tebes como residente en Buenos Aires y el de otros.

Va un ejemplo de la trama enmarañada de personas en Castañumanta. Filemón era un "agregado" en el puesto de Punitayoj, una localidad a más de $70 \mathrm{~km}$ de Pozo del Castaño, donde vivía Andrea, hermana de crianza del autor. Tebes describe a Punitayoj como "mucho monte de algarrobos y quebrachos era, y muy buena agua, con mucha siembra y buenos animales". Filemón era nombrado siempre como comisario de Monte Redondo, dado que ostentaba mucha autoridad en la zona. Don Pasha mandaba "a sus hijos a la escuela del Castaño para que por lo menos supieran leer" (Tebes, 2009, p. 95). Filemón se
3. Nos referimos a que escribe los textos en quichua (agregando los préstamos frecuentes del castellano, sin marcaciones especiales), y no a que escribe solamente en quichua los textos (es decir, sin tomar préstamos frecuentes).

4. Las traducciones al castellano son todas de su colaborador Atila Karlovich. Tomo las traducciones tal como fueron publicadas, sin proponer traducciones propias para este artículo. 
hizo amigo de Etush (Esteban), que era mudo pero se hacía entender. Cuando llegó el servicio militar, Etush no conocía otras poblaciones más que Totorillas y Punitayoj, y por eso tenía mucho miedo de salir fuera de su zona. Filemón manifestó jocosamente: "que vaya Pasha [al servicio militar]". De ese modo, Tebes destaca que esa frase se convirtió en una muletilla solo conocida en esta zona específca, cuando alguien no quería ir a un lugar que no le convenía. "Que vaya Pasha", además de ser un juego de palabras en castellano, además es un indicio importante de la picardía social, que también se manifestaba en la "castilla" de su época. En otro caso significativo, Tebes describe la vida y el habla del anciano Tata Vitula, uno de los primeros en instalarse en El Castaño. "De los quichuistas que he conocido él era el que hablaba la quichua más antigua, y cuando hablaba no se podían casi escuchar los sonidos ' $\mathrm{e}^{\prime} \mathrm{y}$ ' $\mathrm{o}$ '. Y en castilla también solía motear: 'Apinas pulvuta asintan' [apenas asienta el polvo] - solía decir" (2009, p. 199). El caso de Tata Vitula (así como el de tantos otros personajes) muestra la bisagra sociolingüística que significó ese bilingüismo social inestable, articulado al proceso de subsunción de trabajo por capital que iba profundizándose aceleradamente.

Respecto de narraciones animalísticas, investigamos sobre "casos" del zorro (caracterizado por su picardía) en la zona de Cardón Esquina, distante a $60 \mathrm{~km}$ al sur de Pozo del Castaño. Sin embargo, de un total de 83 narraciones y anécdotas, Tebes consigna solamente tres dedicadas a este animal: es una decisión particular de exclusión temática pues, repetimos, estos "casos" siguen siendo numerosos. Pero la innovación va por otro lado: Aguito Ventajero (Agustín) es explícitamente pícaro. Le dicen "ventajero" porque siempre logra salirse con la suya, y aparece varias veces en el memorial de Tebes (2009). Aguito es el personaje que materializa perfectamente el ciclo del zorro (Canal Feijóo, 1951), y actualiza la picardía como un tipo particular de estructura de sentir (Williams 1997 [1977]) que atraviesa toda la trama social rural del Salado Medio (Andreani, 2014). Es evidente la necesidad del autor de describir un personaje de la zona para dar cuenta de una "cultura shalaca" propia, con sus particulares mitos locales. Así como el zorro era un mediador entre los animales y el orden superior (Palleiro, 1997), aquí Aguito actúa como un visible mediador entre peones y capataces (el mundo rural vigente y la subsunción de trabajo por capital) que llegaron a Pozo del Castaño desde la década del veinte y del treinta con los obrajes (Bilbao, 1974; López, 2003). Es la estrategia para presentar un imaginario social shalaco. Ni "Aguito Ventajero", ni Pasha, ni Campitos u otros "pícaros" son personajes "típicos" de una zona rural. Tebes los describe y los integra a su memorial porque busca una autenticidad basada en las experiencias populares reales que componen la estructura social del Salado medio: la trama social que sostiene al quichua. Tebes no recopila como folklorista, sino que rescata vivencias de personas reales que vivieron con él, y desde ahí reconstruye su quichua.

\section{Un tipo de agencia}

En sus estudios, Martínez (2013b) elabora un espacio de tipicidades desde las condiciones de producción del intelectual de provincia. Desarrollaremos algunos de esos puntos, a partir de la idea de que Tebes manifiesta una posición inestable (Bourdieu, 2002) entre un intelectual de provincia y otro propio de un lugar central:

1. El espacio de provincianía carecería de masa crítica cotidiana que favoreciese el intercambio (Martínez, 2013b, p. 175). En este caso, la masa crítica proviene de escasos lin- 
güistas abocados a las lenguas nativas (institutos zonales de lingüística, lingüistas del CONICET y de la UBA, etc.), bilingües escolarizados con capacidad de gestión cultural en Buenos Aires y algunos alumnos del curso universitario de quichua. Pero son especialmente algunos bilingües tradicionalistas de contexto urbano en SdE quienes suelen "juzgar" la autenticidad de algunas obras quichuas, sobre todo si respetan la fidelidad alfabética que consideran como "tradicional" (denominado "signografía", y que en realidad está basado en normas del castellano). En el caso de Castañumanta esta condición no se cumple, porque Tebes utiliza un alfabeto diferente, basado en la estructura interna del quichua. 5

2. Las publicaciones "de autor", autofinanciadas, en un contexto de circulación local y con editoriales poco profesionalizadas (cf. Martínez, 2013b, p. 176). Si bien Tebes publicó esta obra en una editorial no académica como Dunken, esta es de circulación nacional y está impulsada más bien por la legitimidad de su antología crítica anterior de 2006 (publicada por Eudeba y con referato) y también por su coedición de la gramática de Nardi de 2002 (que también salió por Dunken). Esos antecedentes permitieron consolidar una posición especial en la red de socialidad académica porteña y local que guarda cierto interés en las lenguas nativas. ${ }^{6}$

3. La dificultad de profesionalización que asegure dedicación a la tarea (Martínez, 2013b, p. 175). Tebes trabajó en espacios contables de Buenos Aires y se jubiló a comienzos de los años ochenta, cuando comenzó a colaborar con Bravo, de modo muy contingente con el matrimonio de lingüistas norteamericanos Nadine y Donald Burns, y con Ricardo Nardi (antropólogo del Museo de la Plata). Tebes publicó en 1986 un pequeño libro de relatos (La castilla y los shalacos de Figueroa), pero los retiró de circulación inmediatamente: suponemos que hubo obstáculos para el autor. Nunca pudimos acceder a ese material, puesto que ni siquiera sus colaboradores más cercanos lo poseen. Pero hay un indicio de esa modestia, incorporada en el hablante devenido escritor-agente:

Mario era un hombre profundamente pudoroso y absolutamente respetuoso tanto de
su cultura como de su familia (...) me contó anécdotas [y] yo le decía que por qué no
las incluía en el libro y me decía que eso no se podía contar en público, que eso no le
hubiera gustado al tío [X]. No se trataba necesariamente de historias escandalosas, ni
mucho menos, pero había ciertos códigos que a mí se me escapaban que permitían
que un cuento sí se contara y otro no. (Karlovich, comunicación personal,18/12/2016)

Otra interpretación nuestra es que, según su percepción, este primer libro no estaba a la altura de una escritura quichua auténtica, o sentía que escribía mal. Por otra parte, sabemos que Tebes nunca acordó plenamente con el sistema de escritura de su maestro, Domingo Bravo (cf. Tebes, 2009, pp. 274-275). Estado actual del quichua santiagueño fue la primera antología quichua elaborada por Bravo (1965). Pasaron 41 años hasta que otra antología surgiera, pero esta vez basada en una investigación muy exhaustiva, Sisa Pallana, antología de textos quichuas santiagueños (2006) de Tebes y Karlovich, editada por Eudeba. Pero hay otro trabajo de Tebes junto con Lelia Albarracín y Jorge Alderetes (Albarracín et al., 2002) que fue su primer aporte fundamental: se trataba de la edición comentada de los borradores del curso de lingüística quichua que dictaba el antropólogo Ricardo Nardi a mediados de los años ochenta en Buenos Aires. Esto significa que los dos primeros trabajos de Mario Tebes fueron aportes académicos determinantes (una lingüística descriptiva y una antología crítica), y el tercer libro es el Castañumanta, que es narrativa de autor: los tres volúmenes fueron producidos en un período aproximado de nueve años, los últimos de su vida y durante el presente siglo.
5. Un alfabeto quichua estandarizado y utilizado en toda la zona andina, es el denominado como pan-dialectal, que respeta la estructura silábica regular del quechua (estructura CVC: [C] consonante [V] vocal [C] consonante, y no admite grupos internos consonánticos o vocálicos). El alfabeto pan-dialectal es económico en normas ortográficas, está basado principalmente en principios fonológicos pero su aplicación permite respetar relativamente cada variedad dialectal (Albó 1992; Alderetes 2001; Albarracín 2009).

6. En esta red no solo entran santiagueños radicados en Buenos Aires, sino muchos otros. Por ejemplo, el historiador Hugo Chumbita solicitó a Tebes una interpretación y traducción de la Declaración de la Independencia de 1816, una de cuyas versiones estaba escrita en quechua (Karlovich 2006, p. 43). 
4. El intelectual de pueblo

tiene un espacio de referencia acotado a la población en que vive y a las redes de las que forma parte (...) las redes de circulación pueden cruzarse, constituir circuitos y regiones de intercambio según lógicas diversas - que no siempre se articulan en la forma centro-periferia- y que hay que descubrir caso por caso. (Martínez, 2013b, p. 173)

Las redes de socialidad que Tebes describe en su memorial no son unidireccionales (santiagueños que emigran hacia Buenos Aires), sino que la trama varía entre parientes, amigos y vecinos que circulan entre Chaco, Paraguay, Buenos Aires, y ciudades como Clodomira, La Banda y Santiago Capital.

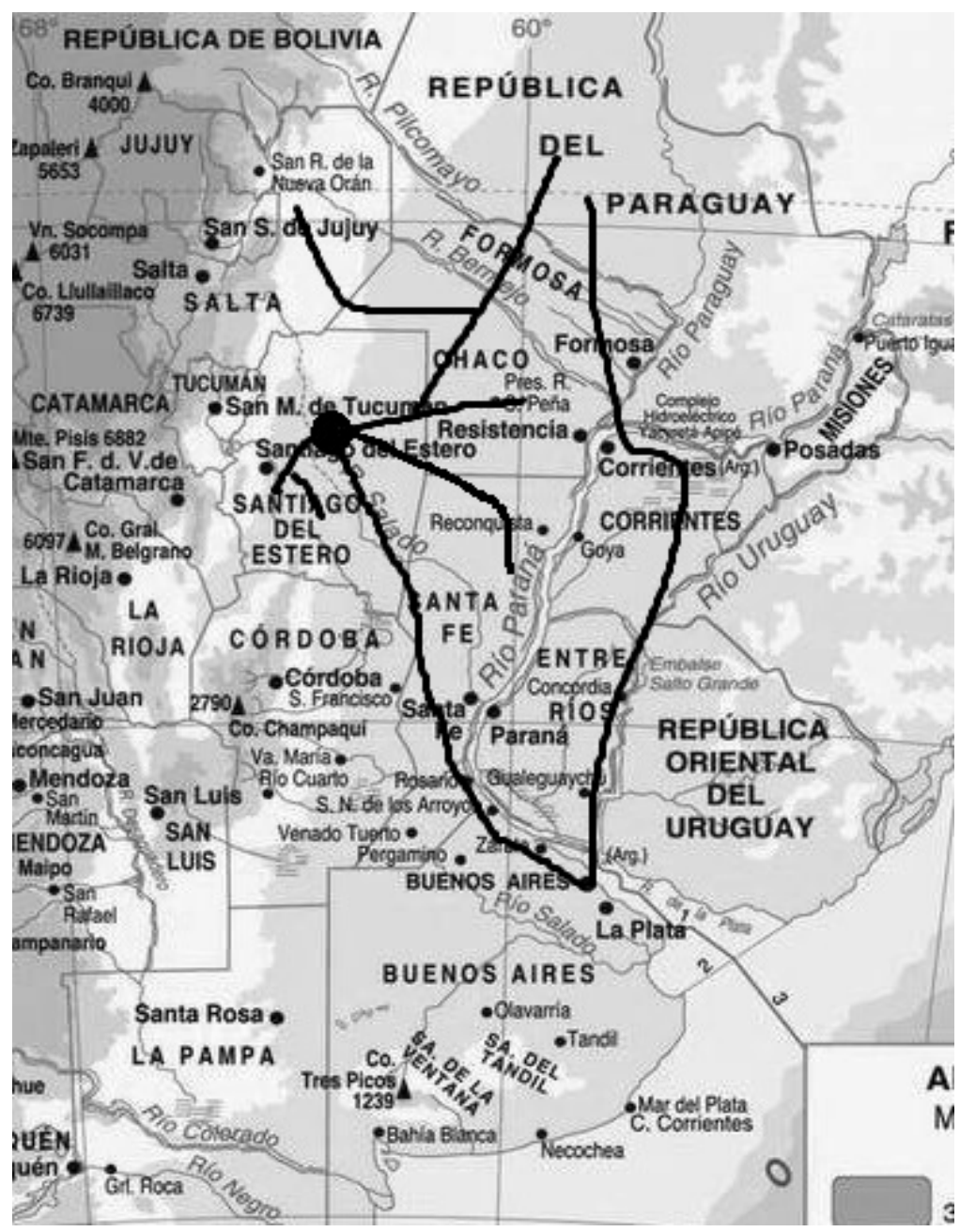

Figura 3: Itinerarios sociales que componen la trama descripta por Tebes en su memorial: migraciones, amigos, peones con trayectos geográficos del Gran Chaco, parientes mayores que recorrieron otras geografías, noticias de la Guerra del Chaco, vivencias con figueroanos en Buenos Aires, entre otras. 


\section{Posicionamientos}

Los "discursos pueden pensarse como tomas de posición en relación con las normas que establecen lo aceptable, lo valioso, etc., vinculadas al lugar de los agentes en el sistema de relaciones" (Díaz, 2009, p. 28). Para pensar la posición de Tebes (es decir, su política textual quichua), nos interesan dos autores quichuistas, Aldo Tévez y Sixto Palavecino:

1. Aldo Tévez, el poeta nacido en la localidad de El Hoyón (departamento de Atamisqui, al sur de Santiago Capital), pertenece desde 1992 a la Academia Mayor de la Lengua Quechua, de Cuzco (AMLQ). Se trata de un consorcio conformado por sacerdotes, militares y terratenientes devenidos lingüistas amateurs que poseen una mirada exacerbada sobre su linaje directo de los emperadores incas y un aparato fonador quechua proveniente de los dioses (cf. Marr, 2002). Qomer Pacha, de Tévez, se compone de traducciones de tangos a quichua, poesías (con explícitas intenciones de vanguardia) con palabras extraídas de otros dialectos quechuas - con lo cual se genera un texto muy complicado de leer-y poemas de otros autores traducidos al quichua. Fruto de nuevos contactos a través de su producción escrita, Tévez ingresó como miembro en la AMLQ. Se le cuestiona un uso casi elitista del idioma, que solo determinados especialistas lograrían comprender totalmente $-\mathrm{y}$ teniendo cerca varios diccionarios de distintas variedades-. Después de la reseña crítica de Tebes y Karlovich a un diccionario de Tévez en 2007 porque no respondía mínimamente a la lexicografía moderna (Nuevo Diario, 02/12/2007), Tévez pidió derecho a réplica en el periódico, donde los acusó de "académicos de marras". Teniendo en cuenta esta polémica de 2007, el Castañumanta de Tebes no refiere a otros dialectos quechuas de la zona andina, no usa voces que el lector quichuahablante local desconoce y no realiza traducciones de otros textos al castellano. En consecuencia, lo que podrían ser atributos de escritura quichua con pretensiones de legitimación de "alta literatura", aquí son omitidos estratégicamente.

2. El músico Sixto Palavecino publicó sus canciones y coplas quichuas en un libro de fines de los ochenta (Dúo Sachero Sixto-Violín) que se ubicaba plenamente en los parámetros del folklore santiagueño. Su relación con Palavecino fue armoniosa. A tal punto, que es el único quichuista extrazonal (no shalaco) incluido en el Castañumanta, lo cual es todo un indicio de posicionamiento del autor: Tebes narra un cuento gracioso sobre una comadre y un compadre que incurren en una relación amorosa, pero Tebes aclara que "yachaspa mana ateq risqayta churapuyta chá picardía churapukoq kasqanta ká qaré tukuy casos siminmanta lloqseqkuna (aunque sepa que no voy a lograr la picardía que ese hombre [Palavecino] le pone a todos los casos que salen de su boca)" (2009, pp. 160-161). Esa modestia de Tebes hacia Palavecino indica un tipo de relación de especial amistad y respeto, un tipo de sociabilidad más cercana a músicos, agentes culturales rurales y lingüistas legitimados en el campo científico, que a bilingües legitimados como miembros de "academias" amateurs con pretensiones hegemónicas, como sería el caso de Aldo Tévez (cf. Albarracín y Alderetes, 2005).

\section{Reglas constitutivas de escritura}

Describimos esta literatura quichua como un espacio de producción discursiva con autonomía inestable, producto de su especificidad sociolingüística (la lengua misma, en su visibilización como escritura) donde los autores disputan solapadamente por dar una definición sobre lo que debería ser la escritura quichua.

Estas prácticas siempre precisan de validación externa (agentes académicos, tradicionalistas, bilingües urbanizados y escolarizados, agentes educativos). Históricamente, la mayoría de textos quichuas fue generada por no-quichuahablantes, como prácticas exógenas de literatura, ensayos y gramáticas. Como 
caso anómalo, "la quichua" nunca fue una marcación estratégica de etnicidad política de las bases sociales (sea en el campesinado organizado, sea en etnogénesis indígenas recientes del espacio rural), pero tampoco lo fue - ni lo es - en las prácticas gubernamentales. Este marco de despolitización de "la quichua" permite entender por qué nunca se manifiesta en una explícita resistencia (política) a nivel lengua, como sí ocurre en otros territorios (NEANOA-Andes), donde la articulación entre etnicidad/lengua se construyó históricamente como marcación política pública. No obstante, sí hay un conflicto lingüístico: el castellano ocupa un lugar totalizador en el espectro social de los géneros discursivos que circulan en la sociedad. Tan intenso es ese tipo de política lingüística, que Tebes busca escribir "para que lo lectores sepan cómo se vivía y hablaba en la Figueroa de los años 30" (2009, p. 29), y que busca "reelaborar la lengua de su infancia por los caminos de la escritura (2009, p. 25)". Esa necesidad de retorno a un estado sociolingüístico "ideal" es clave para (y desde donde) mirar este tipo de discurso.

La búsqueda de autenticidad es doble: a) las coordenadas espacio-temporales determinadas (la quichua shalaca de Figueroa de los años treinta y cuarenta); y b) el trayecto vital del autor, que está presente en toda la obra y en dichas coordenadas. Pero esa autenticidad es posible porque jamás se desliga de su propia memoria social. Así, capitaliza una posición muy singular dentro de "la quichua" escrita.

Un quichua mal o bien escrito es otra regla importante de esta literatura: ese valor en el binomio mal/bien no se funda en aspectos estéticos propios del campo literario en lenguas dominantes, sino que se busca un paralelismo nítido entre escritura y oralidad, porque escribir bien en quichua es reflejar del mejor modo posible el habla.

La migración poblacional y la movilidad permanente son muy recurrentes en el memorial de Tebes. Díaz refiere esto como estrategia de acumulación en el campo folklórico: "Ese modo de vida, identificado con el pago, aparece más valorizado cuando se asocia la nostalgia causada por la pérdida [de ese pago]" (2009, p. 130). Pero Tebes nunca cristaliza esa "pérdida del pago" a través de la añoranza - que es un recurso temático muy frecuente en el folklore y la poesía urbana santiagueña-, sino que su descripción es siempre situada y con personas reales de la zona. En Tebes, la añoranza está atravesada por el proceso vivo de los pobladores recuperados en su memorial. De este modo -en su trayecto de acumulación de capital - cumple con un tema que es muy requerido en la literatura local (la añoranza y la vuelta al pago), pero lo hace con criterios nuevos, siempre reconocidos por él como propios de "su" zona. En Castañumanta, hay un nuevo tratamiento del tema que se sostiene en un recuerdo empírico reconstruido, y no en un discurso folklorizante.

La elección del alfabeto es un elemento conflictivo ineludible. Hay un escenario de disputas - tal vez el más visible sobre el quichua - que refiere el uso de un alfabeto quichua autónomo (denominado generalmente como pandialectal) o un alfabeto castellanizante (denominado localmente como "signografía"). Frecuentemente, el primero es asociado al ámbito académico, y el segundo, al ámbito tradicionalista. Hubo otros alfabetos anteriores a la "signografía" de Bravo (1956), pero consignamos el caso de Ricardo Nardi (Albarracín et al., 2002) y su gramática quichua desde los años setenta hasta su muerte, en 1987. En nuestras entrevistas con Tebes, nos contaba que Nardi y Bravo eran adversarios, aunque Nardi tendía a ignorarlo, pues no lo consideraba como un par dentro del campo científico de la década del ochenta. Nardi fue una referencia 
obligada en círculos extranjeros, Buenos Aires, Córdoba y Tucumán; usaba un alfabeto muy similar al actual pandialectal, cuyos criterios son usados en la mayoría de las lenguas indígenas del mundo, con las adaptaciones de cada caso. Nardi fue el germen para que investigadores más recientes (Alderetes, 2001; Karlovich, 2006; Albarracín, 2009) utilizaran el alfabeto pandialectal, que se alinea al círculo científico internacional (Cerrón Palomino, 1987; Godenzzi, 1992) y con serias diferencias hacia la hispanofilia de Bravo. Pero nótese que, si bien Tebes se identificó plenamente con Nardi, el último texto del Castañumanta es un anecdotario de homenaje a Bravo, y está escrito con la "signografía" (castellanizada) inventada por este:

Cunancama nocká borradoresniyta churani, cayta churachcani hcyna, signografianpi, pero allita yachara paycka nockatacka mana del todo conformaasckancka chaynalla cutinanta chaycka. Yacharapasmi tiasckancunata aycacha cuestiones gramaticales mana pay nisckan ina casckancuna nockapajcka, pero chayraycó manami aycapas ajegaj caraycu. Y nocká pay nisckan inallata, librosninpi, apuntesninpiy clasesninpi, yachachicoj carani alumnostacka [...]. (Tebes, 2009, pp. 274-275)

"Hasta el día de hoy yo escribo mis borradores con la signografía por él ideada [Bravo], aun habiéndole manifestado desde un principio mis dudas, acerca de la pertinencia de algunas grafías adoptadas, y otras cuestiones gramaticales no tan convencionales como esto de las grafías. Sin embargo, nunca discutimos sobre estos temas y, cuando enseñaba a mis alumnos, me atenía estrictamente a sus programas y apuntes". (Trad. Karlovich)

Tebes cuenta que "en privado" escribía con la "signografía" de Bravo (es decir, con normas castellanas), pero su Castañumanta está escrito con el pandialectal (cercano a Nardi), que puede ser leído en cualquier ámbito andino con escritura estandarizada, en ámbitos académicos y en cualquier curso de enseñanza superior donde se dicte quichua $\mathrm{u}$ otro sociolecto de la familia quechua. El antecedente de este alfabeto fue la antología Sisa Pallana, del mismo Tebes y Karlovich (2006), que fue publicado por Eudeba. Tenemos entonces una antología con textos comentados con un abundante aparato crítico, que pasó por un referato académico y que sirvió como material de estudio en los cursos que dictaban Tebes y otros profesores que provenían de su influencia.

Por último, hay un tipo de lector para quien la obra está destinada implícitamente, aunque las formas de circulación casi nunca lleguen a ese grupo en cuestión, porque en el espacio rural/rururbano de SdE es nulo el mercado editorial. Pensamos que estas obras quichuas postulan un lugar social conformado por un destinatario complejo. Se trata de:

1. población rural-urbana proletarizada en territorios con capitales de desarrollo periférico en la primera mitad del siglo XX (Tasso, 2007);

1.1. en cuyas redes de sociabilidad tuvieron que generar repertorios bilingües (quichuacastellano) (Andreani, 2013);

1.2. principalmente mediante los agentes más activos de la subsunción de trabajo por capital (López, 2003) que operaron como puntos bilingües densos;

2. posteriormente reconfigurado ese sector como población sobrante; ${ }^{7}$

2.1 con redes migratorias urbanas hacia zonas centrales (Buenos Aires, principalmente);

2.2. con nuevos regímenes de explotación-subalternización cultural (Ledesma y Tasso, 2011), sostenidos por la modernización estatal en la segunda mitad de dicho siglo (Martínez, 2013a);
7. Uso el concepto de población sobrante o sobrepoblación relativa en el sentido desarrollado por Sartelli: "Se trata de toda esa capa de la clase obrera que no tiene utilidad inmediata para el capital como productor de plusvalía en condiciones de productividad media" (2013, p. 67). Santiago del Estero sufrió un aumento notorio de la población sobrante en las últimas cinco décadas, hecho evidenciado en la reproducción casi nula de su propia estructura productiva y con un $90 \%$ de sostén presupuestario desde el Estado nacional (Desalvo, 2014: p. 136). 
2.3. con nuevas expresiones de esa población sobrante en tramas simbólicas urbanas (extendidas) de bilingüismo de "emblema” y ruralidad exógenamente folklorizada (Grosso, 2008).

Los bilingües referidos implícitamente en estas obras son diversos: pueden residir en Buenos Aires o en SdE, ser gestores culturales transescalares como Tebes o solo reproductores de culturales locales que no se mueven de su pueblo, artistas o musiqueros del monte; obreros rurales muy empobrecidos, comerciantes ascendentes de pequeños parajes bilingües; incluso agentes estatales que llegan a zonas rurales y se convierten en bilingües por las interacciones surgidas en la subsunción de trabajo por capital (y por la escolarización estatal en zonas rurales). Por el tipo de densidad sociodemográfica, pueden poseer una escolarización alta o muy baja, y algunos accedieron a otras capas sociales (bilingües en ámbitos políticos, educativos, burocráticos), y a otros campos (comisionados municipales, gobernadores, rectores, etc.), pero lo relevante es que los últimos son una minoría significativa y no representativa del grueso poblacional bilingüe empobrecido.

\section{Escribir para regresar}

El valor de las escrituras quichuas reside en un tipo particular de autenticidad basado en la pertenencia a una zona sociogeográfica identificada como "quichuista". Poner la lengua en papel, tratar de escribirla es un aspecto ineludible. El viaje de regreso (Pacheco de Oliveira, 2010) se constituye como necesidad de escribir. Si el enunciador es construido por un agente social con un enorme capital simbólico acumulado en el campo (Díaz, 2009, p. 136), la totalidad del memorial escrito hace alusión a su propia trayectoria vital, y ahí reside su estrategia de acumulación de capital simbólico. Nos preguntamos cuál es esa trayectoria. Describimos "postas" posibles en el caso de Tebes:

" la trama social del pospatronazgo, que durante un siglo hasta los años cuarenta-cincuenta del siglo XX, permaneció como una red muy extendida de familias emparentadas, capataces, obreros, etc.; todos ellos con el quichua como lengua de uso social generalizado, hasta finales de ese período;

» el sujeto cuya socialización primaria (familiar y extendida) es intensamente bilingüe y en un contexto rural, con esos resabios de una trama compleja del patronazgo rural decimonónico;

» el emigrado escolar a la ciudad provinciana más cercana, La Banda, lugar adonde confluían los productos del sistema agropecuario de las redes extendidas de Figueroa;

" el shalaco en Buenos Aires, socialización con otros inmigrantes y coprovincianos;

" la movilidad social ascendente del trabajador del "interior";

» contactos con agentes bilingües del Alero Quichua y otros productores culturales (década del setenta);

" contacto inicial con Domingo Bravo (comienzos de los años ochenta);

» Bravo le sugirió - “mejor dicho bien me impuso" (Tebes, 2009: p. 273) - que siguiera a distancia el curso de quichua en la UNSE (SdE); posteriormente se hizo cargo del anexo del curso en Buenos Aires: primero en la Casa de Santiago, después en el Instituto de Lingüística de la UBA;

» el viaje de regreso en su adultez media, respecto de su quichua de la infancia y la juventud: la necesidad de regreso deviene objetivación de la lengua (escritura, investigación, academia, contactos);

» la socialización gradual en el campo científico extraprovincial: se convierte en colaborador y consultante lingüístico (matrimonio de los norteamericanos Burns, en más 
intensidad con Ricardo Nardi en el INA) e intelectuales de provincia (como Bravo), durante la década del ochenta;

» la necesidad de una escritura posible a mediados de los ochenta: no lo convence porque -para Tebes-está "mal" escrito/ problemas de codificación/ inestabilidad del habitus/ campo discursivo quichua;

" replanteo de su regreso: la búsqueda de un saber "total" sobre la lengua recuperada;

" la capitalización ascendente desde una doble pertenencia (rural santiagueña-académica porteña) gradualmente acumulativa:

" simultánea supresión de estrategias del intelectual de provincia en este nuevo posicionamiento de esa "doble" pertenencia, desde la década del noventa hasta entrado el siglo XXI;

" trabajos colaborativos con nuevos investigadores legitimados en el campo académico (Albarracín et al., 2002; Karlovich, 2003, 2006, y algunos de sus alumnos de la UBA que también poseen capital académico);

" el trabajo de recopilación sistemática de documentos quichuas, para publicar como la primera antología en Eudeba, es decir, la posibilidad de una mirada panorámica sobre la literatura quichua desde inicios del siglo XIX hasta 2006;

» publicación desde Eudeba: un reconocimiento centro a periferia (Albarracín et al., 2002; Tebes y Karlovich, 2006);

" mirada panorámica que permite redirigir nuevas energías hacia un memorial de escritura con un estilo deliberado, producto de dicha panorámica (un "estado de arte" quichua);

" el laborioso oficio del escritor "shalaco" anciano, es decir, ausente de marcas académicas entre 2006-2009 (evidencia de que es una estrategia deliberada);

" el producto: un legado sociolingüístico, una población históricamente situada y una lengua, indisolublemente reconstruidos mediante la memoria y la consulta;

" la concreción exitosa de un producto literario "shalaco": la publicación personal de autor (2009).

Pacheco de Oliveira proponía (para el caso de los sertanejos del nordeste brasilero que se autoadscribían indígenas) el concepto del viaje de regreso en tres aspectos: a) como "actualización histórica que no anula el sentimiento de referencia al origen sino que lo refuerza" (2010, p. 27); b) como pertenencia a la tierra; c) como el conjunto de dispositivos de movilidad que implican mantener la etnicidad. La discusión sobre etnicidades reactivas a procesos de aculturación tiene su correlato también en las lenguas. En este caso, no sería una etnicidad indígena sino una automarcación especial de ser bilingüe/ser shalaco, y ese mantenimiento - como el trayecto de Tebes - también implica diversas operatividades con el Estado y la academia.

Pensemos el viaje de regreso como un trayecto que algunos bilingües realizaron respecto de $s u$ quichua, donde fueron determinantes la movilidad socioeconómica y cierto grado de escolarización para acceder a dispositivos de producción cultural estatal (música folklórica, literatura, audiovisuales, asistencia a cursos de quichua, etc.) y visibilizar su bilingüismo como un "emblema". Esta caracterización específica del viaje de regreso no es exclusiva de ancianos quichuistas, sino también de jóvenes que están buscando escribir por nuevas vías (Guillín, 2012) o traducen obras quichuas al castellano con criterios muy originales cmo el caso de la traducción de Basualdo sobre la obra de José Antonio Sosa (2014 [1953]). 


\section{Figura 4}

\begin{tabular}{|c|c|c|c|}
\hline $\begin{array}{l}\text { Criterios } \\
\text { socioeconómicos }\end{array}$ & $\begin{array}{l}\text { Criterios } \\
\text { sociolingüísticos }\end{array}$ & $\begin{array}{l}\text { Reglas generales de } \\
\text { escritura quichua }\end{array}$ & $\begin{array}{l}\text { Estrategias del autor } \\
\text { como agente }\end{array}$ \\
\hline $\begin{array}{l}\text { Subsistencia complementaria } \\
\text { con recursos del monte } \\
\text { (recolección y caza, miel, } \\
\text { algarroba). Movilidad } \\
\text { colectiva por la recolección y } \\
\text { socializaciones festivas en el } \\
\text { monte (Farberman, 2005) }\end{array}$ & $\begin{array}{l}\text { Amplias capas poblacionales } \\
\text { del territorio provincial con } \\
\text { monolingüismo quichua } \\
\text { manifiesto y consolidado } \\
\text { desde el siglo XIX }\end{array}$ & $\begin{array}{l}\text {-Escritos quichuas muy } \\
\text { infrecuentes con carácter } \\
\text { panfletario (ej. contra el } \\
\text { gobierno de Taboada), en } \\
\text { período de desarrollo inicial } \\
\text { de capitalismo agrario, últimas } \\
\text { décadas del siglo XIX. } \\
\text { Amplias capas poblacionales } \\
\text { del territorio provincial con } \\
\text { monolingüismo quichua } \\
\text { manifiesto y consolidado } \\
\text { desde el siglo XIX }\end{array}$ & - \\
\hline $\begin{array}{l}\text { Subsunción de trabajo por } \\
\text { capital: proletarización gradual } \\
\text { (6) }\end{array}$ & $\begin{array}{l}\text { Reconfiguración de tramas } \\
\text { bilingües en nuevos escenarios } \\
\text { urbanos (11) }\end{array}$ & $\begin{array}{l}\text {-Escritores quichuistas con } \\
\text { escolarización (1) (4) } \\
\text {-Necesidad de escritura como } \\
\text { "rescate" (8) } \\
\text { - Géneros tipificados } \\
\text { (adivinanzas, coplas, fábulas) } \\
\text { con intenciones de oralidad } \\
\text { "verídica" (4) }\end{array}$ & $\begin{array}{l}\text { Escritura (no solo oralizante, } \\
\text { como Gil Rojas en el } \\
\text { departamento Copo, por } \\
\text { ejemplo) sino con gran } \\
\text { necesidad de similitud con la } \\
\text { matriz oral }\end{array}$ \\
\hline $\begin{array}{l}\text { Intensificación de la } \\
\text { explotación capitalista de baja } \\
\text { productividad (1ra mitad, siglo } \\
\text { XX) (1) }\end{array}$ & $\begin{array}{l}\text { Nuevas interacciones bilingües, } \\
\text { construidas forzosamente } \\
\text { entre agentes del capital y } \\
\text { poblaciones proletarizadas del } \\
\text { Salado Medio y Norte (años 20, } \\
30,40)(2)\end{array}$ & $\begin{array}{l}\text {-Reminiscencia a un pasado } \\
\text { sociolingüístico ideal ya perdido } \\
\text { (3) } \\
\text {-El idioma se recopila como } \\
\text { "rescate", no se reconstruye en } \\
\text { "estados" anteriores (3) }\end{array}$ & $\begin{array}{l}\text {-Actitud manifiesta de } \\
\text { "reconstrucción" del idioma, } \\
\text { en un quichuista que logró } \\
\text { movilidad social en Buenos } \\
\text { Aires (1) }\end{array}$ \\
\hline $\begin{array}{l}\text { Continuación/degradación de la } \\
\text { trama rural de pos-patronazgo } \\
\text { con numerosas familias } \\
\text { emparentadas, y redes de } \\
\text { alianzas-matrimonios locales (9) }\end{array}$ & $\begin{array}{l}\text { Bilingüismo social } \\
\text { generalizado en la trama pos- } \\
\text { patronazgo (9) }\end{array}$ & & $\begin{array}{l}\text {-Escribir como una forma } \\
\text { de regreso a un quichua } \\
\text { históricamente situado en la } \\
\text { trama social de los años 30- } \\
40 \text { (9) }\end{array}$ \\
\hline \multirow[t]{2}{*}{$\begin{array}{l}\text { Crisis del sistema forestal } \\
(40-60) \\
\text { Sequías históricas (30-40 / } 70 \\
\text { / 80) (7) } \\
\text { Dependencia presupuestaria } \\
\text { del estado provincial al aporte } \\
\text { de nación en un 9o \% (años } 60 \\
\text { hasta siglo XXI) (11) }\end{array}$} & \multirow[t]{2}{*}{$\begin{array}{l}\text {-Eficaces dispositivos de } \\
\text { prohibición lingüística en los } \\
\text { procesos escolares formales } \\
\text { (medio siglo: años 40-5o hasta } \\
\text { 80) (4) }\end{array}$} & $\begin{array}{l}\text {-Recopilación numerosa } \\
\text { de fábulas animalísticas } \\
\text { (principalmente el zorro): } \\
\text { economía de recolección y } \\
\text { caza / explotación capitalista } \\
\text { / dispositivos estatales (6) } \\
\text { (elementos jamás explorados } \\
\text { por los folklorólogos). } \\
\text {-Fábulas sobre el carácter } \\
\text { ahorrativo -en alimentos- de } \\
\text { la iguana u otros animales (7) }\end{array}$ & $\begin{array}{l}\text {-Exposición } \\
\text { (deliberadamente) escasa de } \\
\text { fábulas animalísticas en su } \\
\text { libro (7) } \\
\text {-Descripción de personajes } \\
\text { reales que encarnan el ciclo } \\
\text { "pícaro" del zorro, como } \\
\text { mediadores entre comunidad } \\
\text { y Estado/capital (Aguito, } \\
\text { Clámades, etc.) (2) }\end{array}$ \\
\hline & & $\begin{array}{l}\text {-Mirada poética sobre el } \\
\text { objeto "quichua" (3) }\end{array}$ & $\begin{array}{l}\text {-Escribir con modestia } \\
\text { (repertorio moral) (5) }\end{array}$ \\
\hline \multicolumn{2}{|c|}{$\begin{array}{l}\text { Sujetos bilingües rurales (minoría proporcional) con acceso } \\
\text { gradual a capas asalariadas urbanas (1) }\end{array}$} & $\begin{array}{l}\text {-Reproducción de la } \\
\text { perspectiva mítica de leyendas } \\
\text { (3) }\end{array}$ & $\begin{array}{l}\text {-Reproducción escasísima } \\
\text { de leyendas: con nula mirada } \\
\text { mítica (3), solo evaluación } \\
\text { moral } \\
\text {-Marcaciones solo con } \\
\text { mensaje moral: (hipótesis) } \\
\text { parámetros surgidos de la } \\
\text { trama social post-patronazgo } \\
\text { (9) }\end{array}$ \\
\hline
\end{tabular}


Figura 4 (continaución)

\begin{tabular}{|c|c|c|c|}
\hline $\begin{array}{c}\text { Criterios } \\
\text { socioeconómicos }\end{array}$ & $\begin{array}{c}\text { Criterios } \\
\text { sociolingüísticos }\end{array}$ & $\begin{array}{c}\text { Reglas generales de } \\
\text { escritura quichua }\end{array}$ & $\begin{array}{l}\text { Estrategias del autor } \\
\text { como agente }\end{array}$ \\
\hline $\begin{array}{l}\text {-Migraciones forzosas } \\
\text { (mayoría de los bilingües) a } \\
\text { Buenos Aires } \\
(\text { años } 40,60,80)(10)\end{array}$ & $\begin{array}{l}\text {-Progresivo desplazamiento } \\
\text { del quichua (2da mitad siglo } \\
\text { XX) } \\
\text { - Reconstrucción fragmentada } \\
\text { de tramas “culturales" de } \\
\text { residentes santiagueños } \\
\text { asalariados en Buenos Aires, } \\
\text { en menor medida Rosario (3) }\end{array}$ & $\begin{array}{l}\text {-Constante intento de } \\
\text { innovación estilística (poesía) } \\
\text { y referencias de autenticidad y } \\
\text { naturaleza (copla) durante las } \\
\text { últimas s décadas (de SPR), en } \\
\text { agentes con movilidad social } \\
\text {-Juegos de traducción } \\
\text { de poesías complejas en } \\
\text { castellano al quichua } \\
\text {-Ausencia o escasa } \\
\text { visibilización de } \\
\text { dispositivos estatales (estilo } \\
\text { predominantemente folklórico) }\end{array}$ & $\begin{array}{l}\text {-Descripción del trayecto vital } \\
\text { del autor, mediante narrativas } \\
\text { de otros con vivencias } \\
\text { compartidas (Figueroa, La } \\
\text { Banda, Paraguay, Chaco y } \\
\text { Buenos Aires) (10) } \\
\text {-Descripción de redes } \\
\text { sociales rurales y urbanas que } \\
\text { hablan quichua (10) } \\
\text {-Gran presencia de } \\
\text { dispositivos de modernización } \\
\text { estatal en el espacio rural (11) }\end{array}$ \\
\hline $\begin{array}{l}\text {-Progresiva precarización } \\
\text { laboral local (años 70 hasta } \\
\text { siglo XX) }\end{array}$ & $\begin{array}{l}\text { Consolidación de la asimetría } \\
\text { entre quichua y castellano } \\
\text { como formación estatal de } \\
\text { alteridad lingüística (8) }\end{array}$ & $\begin{array}{l}\text { Escrituras quichuas (en su gran } \\
\text { mayoría) con traducciones } \\
\text { endógenas o exógenas (12) }\end{array}$ & $\begin{array}{l}\text { Escritura quichua sin } \\
\text { traducción deliberada del autor } \\
\text { (al castellano), y traducción de } \\
\text { un colaborador exógeno ( } 12\end{array}$ \\
\hline \multirow{2}{*}{$\begin{array}{l}\text {-Consolidación de la } \\
\text { población sobrante o } \\
\text { sobrepoblación relativa - } \\
\text { SPR- (2da mitad, siglo XX) }\end{array}$} & & $\begin{array}{l}\text { Escritura identificada con el } \\
\text { campo folklórico ( } 5 \text { décadas de } \\
\text { SPR) (13) }\end{array}$ & $\begin{array}{l}\text { Escritura ausente de marcas } \\
\text { folklóricas: por ejemplo, Mate } \\
\text { Cocido no es folklore, sino que } \\
\text { fue el jefe de la banda donde } \\
\text { estuvo como integrante su tío } \\
\text { Vangi (tío de Tebes) (13) }\end{array}$ \\
\hline & \multicolumn{2}{|c|}{$\begin{array}{l}\text { Elaboración histórica de alfabetos en pugna como punto } \\
\text { conflictivo (5) (años 8o hasta siglo XXI): } \\
\text { - Alfabeto unificador pan-dialectal andino autónomo } \\
\text { - Alfabeto dependiente de normas del castellano } \\
\text { (denominada "signografía" por Bravo) (14) }\end{array}$} & $\begin{array}{l}\text { Elección deliberada de un } \\
\text { alfabeto (pan-dialectal) } \\
\text { disociado del espacio } \\
\text { tradicionalista local, como } \\
\text { estrategia del autor para } \\
\text { estandarizar (5) (en la } \\
\text { intimidad, escribe con } \\
\text { "signografía" -14- ) }\end{array}$ \\
\hline
\end{tabular}

Figura 4: Cuadro comparativo que desarrolla desde criterios socioeconómicos hasta las estrategias de Tebes como agente de escritura quichua. Los números entre paréntesis indican referencias cruzadas entre los datos de cada columna: relaciones (hipotéticas) de causa-consecuencia, y eventualmente de oposición entre las referencias.

\section{Final}

Dado este escenario, es posible mirar procesos sociales complejos a través de la ventana que abre una obra quichua, transida de una historicidad conflictiva de larga data. A la vez, exploramos condicionantes materiales y simbólicas para entender la singularidad de esta obra. Muchos elementos descritos aquí permiten una lectura no localista de un fenómeno como una lengua nativa, cuya visibilización debiera ser aparente o exclusivamente local. Son numerosos los factores de desplazamiento lingüístico: pudo haber sido genocidio, esclavitud, violencia estatal, terrorismo. Pero no es este el caso del quichua santiagueño, pues se trató de un proceso en el que se cruzan otros aspectos:

I. la subsunción de trabajo por capital - ganadería por obraje forestal- en esta zona norte del Chaco santiagueño (Bilbao, 1974);

II. la migración poblacional forzada (Tasso, 2011);

III. la prohibición lingüística (Gandulfo, 2007), intensamente aplicada como dispositivo escolar;

IV. la hegemonía cultural (lengua del Estado, cultura escrita, radios, ideología del progreso urbano);

V. conformación de la población sobrante (Sartelli, 2013) en las provincias con capitales 
periféricos -en los últimos 50 años-, que impacta notoriamente en el carácter sociolingüístico de los monolingües quichuas devenidos bilingües Q-C.

Estos cinco aspectos develan la dinámica sociolingüística de un discurso identitario, oculto en un libro de relatos orales. Esto pudo ser descripto, no desde la delimitación arbitraria a un autor y sus elecciones individuales, sino a partir de un proceso sociohistórico denso que lo atraviesa. Siendo shalaco, migrante, asalariado, que en su ancianidad temprana realiza un viaje de regreso hacia su lengua de sociabilidad familiar pero en forma de escritura, no exenta de numerosos escollos en el camino de su memoria, devenido quichuista objetivado, periférico del ámbito folklórico pero colaborador de investigadores, devenido investigador, lector de otras escrituras, devenido escritor shalaco y quichuista: el trayecto inusual de Tebes como bilingüe muestra esa posición inestable (Bourdieu, 2002). En muchas lenguas nativas con amenaza de desplazamiento, la escritura deviene un fetiche (Lazzari, 2010). Es un uso muy singular de un discurso identitario, porque el quichua escrito es una marcación aceptable de alteridad lingüística dentro de la configuración estatal. Lo importante es entender la centralidad de esa escritura en la lengua nativa (lengua periférica del mapa nacional) porque es el emblema de su propia marcación identitaria frente a la asimetría de otras prácticas y discursos que atentan contra su existencia.

Este trabajo intentó presentar la dialéctica entre la historia social que atraviesa a un autor y su producción escrita, y la tensión sociolingüística que constituye a una sobrepoblación relativa de Argentina, como condicionantes de un espacio discursivo que perduró de modo casi invisible durante más de siete décadas. Pero a la vez es existente, con sujetos emergentes que buscan (necesitan regresar lingüísticamente para) convertirse en agentes. Una escritura artificiosa sin un pasado en el que sostenerse, que a su vez intenta reconstruir su matriz oral para ser auténtica, mientras busca existir con los mismos dispositivos estatales que la negaron. 


\section{Q 8. Referencias bibliográficas}

" Ábalos, J. W. (1949). Shunko. Buenos Aires: Losada.

"Ábalos, J. W. (1975). Shalacos. Buenos Aires: Losada.

》Abregú Virreyra. (1942). Idiomas aborígenes de la República Argentina. Buenos Aires: Espasa-Calpe.

»Albarracín, L., Tebes, M. y Alderetes, J. (2002). El quichua santiagueño por Ricardo J. L. Nardi. Buenos Aires: Dunken.

"Albarracín, L. y Alderetes, J. (2005). Lengua y poder. Los hermanos hegemónicos de Argentina. En L. Grabner-Coronel y S. Coronel Molina (Comps.), Lenguas e identidades de los Andes. Perspectivas ideológicas y culturales. Quito: Abya-Yala, pp. 251-292.

»Albó, X. (1992). Criterios fundamentales para un alfabeto funcional del quechua. En J. C. Godenzzi (Comp.), El quechua en debate. Ideología, normalización y enseñanza. Cusco: Centro de Estudios Regionales y Andinos “Bartolomé de las Casas”, pp. 109-120.

》 Andreani, H. (2013). Escuela castellana en monte saladino. Procesos de territorialización lingüística en Figueroa, Santiago del Estero (1920-2010). Papeles de Trabajo - Centro de Estudios Interdisciplinarios en Etnolinguî́stica y Antropología Sociocultural, 1-22.

» Andreani, H. (2014). Quichuas, picardías y zorros. Conflictos y tácticas en una comunidad bilingüe. Santiago del Estero: EDUNSE.

"Aracil, L. V. (1976). Conflit linguistique et normalisation linguistique dans l'Europe nouvelle. Perpignan: Centre Universitaire de Perpignan. Faculté Pluridisciplinaire des Sciences Humaines et Sociales.

" Bilbao, S. (1974). Poblamiento y actividad humana en el extremo norte del Chaco Santiagueño. Cuadernos del Instituto Nacional de Antropología, 5, 143-206.

» Bravo, D. (1956). El quichua santiagueño, reducto idiomático argentino. San Miguel de Tucumán: Universidad Nacional de Tucumán.

» Bravo, D. (1965). Estado actual del quichua santiagueño. Tucumán: Universidad Nacional de Tucumán.

»Bourdieu, P. (2002 [1995]). Las reglas del arte. Génesis y estructura del campo literario. Madrid: Anagrama.

»Canal Feijóo, B. (1937). Ensayo sobre la expresión popular artística en Santiago del Estero. Buenos Aires: Compañía Impresora Argentina.

»Canal Feijóo, B. (1951). Burla, credo, culpa en la creación anónima. Sociología, etnología y psicología en el folklore. Buenos Aires: Nova.

"Cerrón Palomino, R. (1987). Gramática quechua. Cuzco: Centro de Estudios Regionales-Andinos "Bartolomé de las Casas".

" Chamosa, O. (2008). Indigenous or Criollo. The myth of the White Argentina in Tucuman's Calchaquí Valley. Hispanic Amewrican Historical Review, 88(I), pp. 71-106.

»Chamosa, O. (2012). Breve historia del folklore argentino. 1920-1970: Identidad, política y nación. Buenos Aires: Edhasa.

"Chein, D. (2005). La construcción social en los cuentos del zorro en el período de emergencia del campo de la folklorología. En M. I. Palleiro (Comp.), Narrativa: Identidades y memorias (pp. 71-88). Buenos Aires: Dunken. 
»Dargoltz, R. (2003). Hacha y quebracho. Historia social y ecológica de Santiago del Estero. Santiago del Estero: Marcos Vizoso.

»Desalvo, A. (2014). La intervención del estado nacional en la reproducción de la sobrepoblación relativa de Santiago del Estero. DAAPGE, año 14, № 22, pp. 129-152.

" Díaz, C. (2009). Variaciones sobre el ser nacional. Una aproximación sociodiscursiva al foIklore argentino. Córdoba: Recovecos.

»Di Lullo, O. (1937). El bosque sin leyenda: ensayo económico y social. Santiago del Estero: Edición del autor.

" Farberman, J. (2005). Las salamancas de Lorenza. Magia, hechicería y curanderismo en el Tucumán colonial. Buenos Aires: Siglo XXI.

" Gandulfo, C. (2007). Entiendo pero no hablo: El guaraní acorrentinado en una escuela rural: Usos y significaciones. Buenos Aires: Antropofagia.

" Gil Rojas, A. 1954. El Ckaparilo. Santiago del Estero: Edición del autor.

" Gil Rojas, A. (1962). Los tipos de mi fogón. Santiago del Estero: Edición del autor.

" Godenzzi, J. C. (1992). El quechua en debate. Cuzco: Centro de Estudios Regionales-Andinos "Bartolomé de las Casas".

» Grosso, J. L. (2008). Indios muertos, negros invisibles. Hegemonía, identidad y añoranza, Córdoba: Encuentro.

» Guillín, C.; López, O.; Torrez, A.; Pérez, M.; Guillín, R.; Barraza, E.; Guillín, C. (2012). Wawqes Pukllas. Libro juvenil quichua. Buenos Aires: En el aura del sauce.

» Hernández, J. 1991 [1872]. Martín Fierro. Versión al quichua por Sixto Palavecino. Santiago del Estero: Marcos Vizoso.

» Hernández, J. (2007 [1872]). Martín Fierro. Versión al quichua por Sixto Palavecino. Santiago del Estero: Talleres El Liberal.

" Hornberger, N. (1995). Escrituralidad, preservación de la lengua y derechos humanos lingüísticos: tres casos ilustrativos. Alteridades, 5(10), 67-78.

" Karlovich, A. (2006). De la oralidad a la escritura (estudio preliminar). En M. Tebes y A. Karlovich (comps.) Sisa Pallana: antología de textos quichuas santiagueños (pp. 15-41). Buenos Aires: Eudeba.

» Kuz, C. (2001). Domingo Bravo y la invención de la cultura quichua en Santiago del Estero. Tesis de Maestría (inédita), Universidad de Río de Janeiro.

»Landsman, M. E. (2000). La lengua en la dominación política (Del Quichua de Santiago del Estero). VI Congreso Internacional de la lengua Quechua. Santiago del Estero, Argentina. 18 al 14 de octubre.

»Lazzari, A. (2010). Autenticidad, sospecha y autonomía: la recuperación de la lengua y el reconocimiento del pueblo rankülche en La Pampa. En G. Gordillo y S. Hirsch (Comps), Movilizaciones indígenas e identidades en disputa en Argentina. Buenos Aires: La Crujía, pp. s/r.

"Ledesma, R.; Tasso, A. (2011). Empleo rural y migrante estacional en Santiago del Estero. En: Ledesma, R.; Paz, J.; Tasso, A. (eds.). Trabajo rural estacional de Santiago del Estero. Buenos Aires: Ministerio de Trabajo, Empleo y Seguridad Social-OIT

» López, Á. L. (1950 [1938]). Narraciones y leyendas supersticiosas y misterios que encierra El desierto saladino, Primera parte, 2da. edición. Buenos Aires: Librería Perlado.

» López, J. L. (2003). Tierra y trabajo en Pozo del Castaño. Formas de subsunción de trabajo por el capital en una comunidad rural de Santiago del Estero. Tesis de grado en antropología (inédita). Buenos Aires: Universidad de Buenos Aires. 
» Marr, T. (2002). Language Ideology, ownership and maintenance. The discourse of the Academia Mayor de la Lengua Quechua. Opportunities and challengues of bilingüalism. Contributions to the Sociology of Language (Número especial), 87, 199-219.

» Martínez, A. T (2013a). Cultura, sociedad y poder en Argentina. La modernización periférica de Santiago del Estero. Santiago del Estero: EDUNSE.

» Martínez, A. T. (2013b). Intelectuales de provincia. Entre lo local y lo periférico. Prismas, Revista de Historia Intelectual, 17, 169-180.

» Pacheco de Oliveira, J. (2010). ¿Una etnología de los indios misturados? Identidades étnicas y territorialización en el Nordeste del Brasil”. En: Desacatos № 33, mayo-agosto, pp. 13-32.

»Palavecino, S. (1997). Dúo sachero Sixto-Violín. Santiago del Estero: Sigma.

» Palleiro, M. I. (Comp.) (1997). La fiesta en el cielo. Cuentos populares de animales. Buenos Aires: Ediciones del Sol.

»Ruiz Gerez, E. (1963). Santiago del Estero en sus vivencias folklóricas. Rosario: Edición del autor.

»Salto, V. J. (1969). Para Yacu (Agua de Lluvia). Santiago del Estero: Edición del autor.

»Sartelli, E. (2013). De los indígenas chiapanecos y los piqueteros argentinos a los indignados españoles: la rebelión mundial de la población sobrante y los dilemas de la conciencia de clase y la revolución socialista a comienzos del siglo XXI. Projeto História, 46, 63-90.

»Sosa, J. A. (1953). Pallaspa chinkas richkajita (Juntando lo que se va perdiendo), poema quichua, Villa Atamizki. Santiago del Estero: Edición del autor.

»Sosa, J. A. (2014 [1953]). Pallaspa Chinkas Richkaqta. Traducción de Sebastián Basualdo y revisión de Lelia Albarracín. Santiago del Estero: ADILQ.

»Stark L. R. (1985). Historia del Quichua de Santiago del Estero. En H. M. Klein y L. R. Stark (Eds.), South American Indian Languages: Retrospect and Prospect (pp. 732-752). Austin (Texas): Universidad de Texas.

»Tasso, A. (2007). Ferrocarril, quebracho y alfalfa. Un ciclo de economía capitalista en Santiago del estero. 1870-1940. Buenos Aires: Alción.

»Tasso, A. (2011). La sequía de 1937 en Santiago del Estero. Antecedentes y consecuencias de un acontecimiento ambiental. Trabajo y Sociedad, 17(15), 17-39.

» Tebes, M. (2009). Castañumanta Yuyayniy, ni los años ni la distancia. Buenos Aires: Dunken.

» Tebes, M. C., Karlovich, A. F. (2006). Sisa Pallana: antología de textos quichuas santiagueños. Buenos Aires: Eudeba.

» Tévez, A. (1996). Ckomer Pacha (Tiempo de Primavera). Buenos Aires: H\&P.

》 Vigil, N. (2004). Acciones para desarrollar la escritura en lenguas indígenas. Glosas Didácticas, 12, 174-183.

»Unamuno, V. (2012). Bilingüismo y Educación intercultural Bilingüe: miradas en cruce. En V. Unamuno y A. Maldonado (Comps.), Prácticas y repertorios plurilingües en Argentina. Buenos Aires: Edición de los autores. Grup de Recerca en Ensenyament i Interacció Plurilingües (GREIP), pp. 235-250.

» Williams, R. (1997 [1977]). Marxismo y literatura. Barcelona: Península. 
